\title{
Sensitivity of Ascochyta Species Infecting Pea, Lentil, and Chickpea to Boscalid, Fluxapyroxad, and Prothioconazole
}

Erin Lonergan, Plant Sciences and Plant Pathology Department, Montana State University, Bozeman 59717; Julie Pasche, Department of Plant Pathology, North Dakota State University, Fargo 58108; and Linnea Skoglund and Mary Burrows, Plant Sciences and Plant Pathology Department, Montana State University

\begin{abstract}
Lonergan, E., Pasche, J., Skoglund, L., and Burrows, M. 2015. Sensitivity of Ascochyta species infecting pea, lentil, and chickpea to boscalid, fluxapyroxad, and prothioconazole. Plant Dis. 99:1254-1260.

Management of Ascochyta blight in pea, lentil, and chickpea relies on repeated fungicide applications, which has led to development of fungicide resistance and disease control failures in some systems. In vitro assays were conducted to determine baseline fungicide sensitivity in Mycosphaerella pinodes (Ascochyta pinodes), A. lentis, and A. rabiei populations to the demethylation-inhibiting fungicide prothioconazole and the succinate dehydrogenase-inhibiting fungicides boscalid and fluxapyroxad by determining the effective concentration at which $50 \%$ of germination or fungal growth was inhibited $\left(\mathrm{EC}_{50}\right)$. Mean boscalid $\mathrm{EC}_{50}$ values from conidial germination assays were $0.669,0.639$, and $0.171 \mu \mathrm{g} / \mathrm{ml}$

and from mycelial growth assays were $0.258,0.791$, and $0.443 \mu \mathrm{g} / \mathrm{ml}$ for M. pinodes, A. lentis, and A. rabiei, respectively. Mean fluxapyroxad $\mathrm{EC}_{50}$ values were $0.050,0.763$, and $0.057 \mu \mathrm{g} / \mathrm{ml}$ for $M$. pinodes, A. lentis, and A. rabiei, respectively. Mean baseline $\mathrm{EC}_{50}$ values for prothioconazole with mycelial growth were $0.541,0.604$, and $0.283 \mu \mathrm{g} / \mathrm{ml}$ for M. pinodes, A. lentis, and A. rabiei, respectively. A single discriminatory fungicide concentration of $1 \mu \mathrm{g} / \mathrm{ml}$ was selected for all species. Established sensitivity profiles and discriminatory concentrations will be used to monitor sensitivity shifts in populations of Ascochyta spp. and to make effective disease management recommendations.
\end{abstract}

The production of the pulse crops pea (Pisum sativum L.), lentil (Lens culinaris Medik.), and chickpea (Cicer arietinum L.) is a rapidly expanding industry in the Northern Great Plains, especially in North Dakota and Montana, which have led the nation in pea and lentil production since 2002 and 2004, respectively (Lee 2011; United States Department of Agriculture \& National Agriculture Statistics Service 2014). However, pulse growers face a major challenge in the management of Ascochyta blights (AB), host specific diseases caused by Ascochyta lentis Vassiljevsky (causal agent of $\mathrm{AB}$ of lentil), A. rabiei (Pass.) Labr. (agent of AB of chickpea), and Mycosphaerella pinodes (Berk. \& A. Bloxam) Vestergr. (Ascochyta pinodes), (agent of $\mathrm{AB}$ of pea) (Chen et al. 2011; Kraft and Pfleger 2001). These widespread diseases can cause devastating yield losses under favorable climatic conditions and are considered some of the most important diseases affecting pulse crops in the United States and Canada, highlighting the importance of disease management (Bretag et al. 2006; Gan et al. 2006; Ye et al. 2000).

$\mathrm{AB}$ are typically managed with seed treatment and foliar fungicide applications. Although AB can be reduced through the use of resistant cultivars and cultural practices (crop rotation, sowing depth, and stubble management), the use of foliar fungicides is essential to achieving acceptable levels of disease control (Chongo et al. 2003; Davidson and Kimber 2007; Gan et al. 2006). Protectant fungicide (chlorothalonil) can delay the onset of $\mathrm{AB}$; however, once symptoms are present, the application of fungicides that provide a premium level of control is necessary (Davidson and Kimber 2007, Gan et al. 2006). Three fungicide classes that provide the best control and are registered for the management of $\mathrm{AB}$ include quinone outside inhibitors (QoI; Fungicide Resistance Action Committee [FRAC] code 11), demethylation inhibitors (DMI; FRAC code 3), and succinate dehydrogenase inhibitors (SDHI; FRAC code 7)

Corresponding author: Dr. Mary Burrows, mburrows@montana.edu, 406994-7766

Accepted for publication 19 February 2015.

http://dx.doi.org/10.1094/PDIS-06-14-0620-RE

(C) 2015 The American Phytopathological Society
(Burrows 2013). These fungicides are considered to have high to medium risk of developing resistance, a concern that is heightened by the polycyclic nature of the diseases and abundant sporulation of $\mathrm{AB}$ pathogens necessitating repeated fungicide applications (Brent and Holloman 2007; Fungicide Resistance Action Committee 2013; Tivoli and Banniza 2007).

Since registration in 2003, QoI fungicides have been the most widely used postinfection fungicide class in the management of $\mathrm{AB}$ in the United States and Canada (Bowness 2013; Wise et al. 2008). However, resistance to QoI fungicides has been detected in A. rabiei populations since 2007 and in M. pinodes populations since 2010 in the Northern Great Plains and Canada, resulting in recommendations that they be used judiciously in $\mathrm{AB}$ management programs for chickpea and pea fields in these regions (Bowness 2013; Chang et al. 2007; Delgado et al. 2012; Wise et al. 2009). The increasing prevalence of QoI-resistant A. rabiei in North Dakota and Montana has led to an increased reliance on the DMI fungicide prothioconazole (Delgado et al. 2011) (Proline; Bayer CropScience), and it is likely that the use of the SDHI fungicides boscalid (Endura; BASF Corporation, Research Triangle Park, NC) and fluxapyroxad (Priaxor; BASF Corporation) will continue to become more widespread. The importance of establishing early fungicide monitoring programs for $\mathrm{AB}$ resistance to $\mathrm{DMI}$ and SDHI fungicides is emphasized by loss of sensitivity as well as the development of cross and multiple resistances to fungicides in these classes in other plant pathogens affecting horticultural and field crops (Avenot and Michailides 2007; Avenot et al. 2008, 2014; Chen et al. 2013; Forster et al. 2011; Fungicide Resistance Action Committee 2013; Gudmestad et al. 2013; Luo and Schnabel 2008; Thomas et al. 2012; Wyand and Brown 2005).

The accurate assessment of fungicide sensitivity in Ascochyta populations is a critical component in prolonging the use of the limited number of fungicide modes of action available for $\mathrm{AB}$ management in pulse crops. Establishing baseline sensitivity profiles is the first step to detecting shifts in pathogen sensitivity, to ensure that appropriate resistance management practices are recommended and their effectiveness monitored. Sensitivity profiles are typically determined using in vitro assays such as spore germination and mycelial growth. For fungicides that are effective against multiple growth stages, mycelial growth assays may require less time and resources than spore germination assays. Once baseline sensitivity profiles are established, 
the use of a discriminatory fungicide concentration is an efficient method for use in high-throughput pathogen sensitivity surveys (Jo et al. 2006).

Proactive monitoring programs for fungicide resistance in populations of $\mathrm{AB}$ pathogens have been initiated with the goal of detecting shifts in sensitivity at an early stage (Bowness 2013; Delgado et al. 2011; Wise et al. 2008, 2011). Baseline sensitivity profiles for $M$. pinodes and A. rabiei to QoI fungicides have been determined and discriminatory doses are currently being used to monitor sensitivity shifts in pathogen populations (Bowness 2013; Delgado et al. 2012; Wise et al. 2008, 2009). Baseline sensitivities have also been established for A. rabiei and M. pinodes to prothioconazole and for A. rabiei to boscalid (Delgado et al. 2011; Wise et al. 2008, 2011). Therefore, the objectives of this study were to (i) determine the sensitivity of $2012 \mathrm{M}$. pinodes and A. lentis isolates to boscalid and prothioconazole; (ii) determine the sensitivity of $2012 \mathrm{M}$. pinodes and $A$. lentis isolates and baseline $A$. rabiei isolates to fluxapyroxad; and (iii) simplify fungicide resistance monitoring in A. rabiei, $M$. pinodes, and $A$. lentis by developing mycelial growth assays for evaluating sensitivity to boscalid.

\section{Materials and Methods}

Collections of M. pinodes, A. lentis, and A. rabiei isolates. In all, $30 \mathrm{M}$. pinodes, $20 \mathrm{~A}$. lentis, and $30 \mathrm{~A}$. rabiei isolates were selected for this study (Table 1 ). $M$. pinodes and $A$. lentis isolates were arbitrarily selected from culture collections established from infected pea and lentil samples grown in Montana during the 2012 season. M. pinodes and $A$. lentis isolates were collected prior to the registration of fluxapyroxad but not prior to the registration of prothioconazole and boscalid. However, isolates were collected from pea and lentil fields that likely had minimal exposure to prothioconazole and boscalid and where fungicides were effectively controlling $\mathrm{AB}$. Therefore, the $A$. lentis isolates are being considered a functional baseline for the purpose of this study (Russel 2004). A. rabiei isolates collected from the Pacific Northwest were used to validate methods for boscalid and prothioconazole used in previous research and allow the comparison with fluxapyroxad on a true SDHI baseline population (Wise et al. 2008, 2011). A. rabiei isolates collected from 1983 to 2003 with no exposure to prothioconazole, boscalid, or fluxapyroxad were obtained from the United State Department of Agriculture-Agriculture Research Service Grain Legume Genetics unit and the Plant Introduction and Testing Unit Ascochyta collections in Pullman, WA for use in this study and represent a subset of those used in previous research (Wise et al. 2008).
Boscalid conidial germination assays. Boscalid sensitivity was determined by evaluating conidial germination on solid, fullstrength potato dextrose agar (PDA; EMD Chemicals, Gibbstown, $\mathrm{NJ})$ amended at fungicide concentrations of $0,0.001,0.01,0.1$, 1.0 , and $10.0 \mu \mathrm{g} / \mathrm{ml}$ from stock concentrations of technical-grade boscalid (99\% active ingredient [a.i.]; BASF Corporation) serially diluted in acetone following previously developed methods with slight modifications (Wise et al. 2008). Salicylhydroxamic acid was added at $100 \mu \mathrm{g} / \mathrm{ml}$, dissolved in methanol to prevent the fungal pathogen from using an alternative respiration pathway during conidial germination (Wise et al. 2008). All amendments were added to autoclaved media after media had cooled to $50^{\circ} \mathrm{C}$, with the final concentration of acetone or methanol in amended and nonamended media equaling $0.1 \%$ by volume.

All M. pinodes, A. lentis, and A. rabiei isolates were grown on an oatmeal agar medium (Becton Dickinson, Sparks, MD) to induce pycnidial production. Once pycnidia had formed, all isolates were prepared for germination assays using previously developed methods (Wise et al. 2008). Briefly, $5 \mathrm{ml}$ of $0.05 \%$ Tween 20 (Sigma-Aldrich) was added to 7- to 10-day-old cultures and conidia were allowed to passively discharge into solution. The resulting conidial solution was diluted to approximately $2 \times 10^{5}$ conidia/ml using a hemacytometer. A conidial suspension $(200 \mu \mathrm{l})$ of each isolate was pipetted onto each of two replicate plates ( 60 by $15 \mathrm{~mm}$ ) containing solid PDA medium. Plates were incubated at $20 \pm 2^{\circ} \mathrm{C}$ for $18 \mathrm{~h}$ in the dark, after which 100 conidia/plate were evaluated microscopically for germination. Conidia were considered germinated if the germ tube was at least the length of the conidium (Wise et al. 2008). Conidial germination for each replicate was converted to percent inhibition compared with the nontreated control using the following formula: $100-$ [(percent germination of fungicide-amended/percent growth of nonamended) $\times$ 100]. The fungicide concentration that effectively inhibited conidial germination by $50 \%$ of the nontreated control $\left(\mathrm{EC}_{50}\right)$ was determined for each isolate by linear interpolation using the two concentrations that bracketed 50\% (Pasche et al. 2004).

Boscalid, fluxapyroxad, and prothioconazole mycelial growth assays. Stock solutions of technical-grade boscalid (99\% a.i.; BASF Corporation) and prothioconazole (97.7\% a.i.; Bayer CropScience) were prepared at concentrations of $100 \mathrm{mg} / \mathrm{ml}$ and serially diluted in acetone. Stock solutions of formulated fluxapyroxad (Sercadis at $300 \mathrm{~g} / \mathrm{liter}$; BASF Corporation) were prepared at concentrations of $300 \mathrm{mg} / \mathrm{ml}$ and serially diluted in sterile, deionized water. Prothioconazole, boscalid, and fluxapyroxad sensitivity were determined by measuring mycelial growth for each species (M. pinodes,

Table 1. Collection information for Ascochyta rabiei $(n=30)$, Mycosphaerella pinodes $(n=30)$, and A. lentis $(n=20)$ isolates

\begin{tabular}{|c|c|c|c|c|c|c|c|c|}
\hline \multicolumn{3}{|c|}{ A. rabiei } & \multicolumn{3}{|c|}{ M. pinodes } & \multicolumn{3}{|c|}{ A. lentis } \\
\hline Year & Location & $N^{\mathbf{a}}$ & Year & Location & $N^{\mathbf{a}}$ & Year & Location & $N^{\mathbf{a}}$ \\
\hline 1983 & Pullman, WA & 3 & 2012 & Wolf Point, MT & 3 & 2012 & Plentywood, MT & 1 \\
\hline 1984 & Pullman, WA & 1 & 2012 & Opheim, MT & 5 & 2012 & Flaxville, MT & 1 \\
\hline 1984 & Genesee, ID & 1 & 2012 & Nashua, MT & 2 & 2012 & Circle, MT & 1 \\
\hline 1987 & Genesee, ID & 2 & 2012 & Scobey, MT & 8 & 2012 & Raymond, MT & 1 \\
\hline 1987 & Kendrick, ID & 2 & 2012 & Cut Bank, MT & 1 & 2012 & Phillips County, MT & 12 \\
\hline 1987 & Lapwai, ID & 3 & 2012 & Glasgow, MT & 1 & 2012 & Opheim, MT & 2 \\
\hline 1987 & Nez Pierce County, ID & 3 & 2012 & Larslan, MT & 3 & 2012 & Scobey, MT & 2 \\
\hline 1994 & Genesee, ID & 1 & 2012 & Turner, MT & 1 & $\ldots$ & $\ldots$ & $\ldots$ \\
\hline 1995 & Albion, WA & 1 & 2012 & Havre, MT & 1 & $\ldots$ & $\ldots$ & $\ldots$ \\
\hline 1995 & Genesee, ID & 2 & 2012 & Shelby, MT & 1 & $\ldots$ & $\ldots$ & $\ldots$ \\
\hline 1995 & La Grande, OR & 1 & 2012 & Frazer, MT & 1 & $\ldots$ & $\ldots$ & $\ldots$ \\
\hline 1995 & Steptoe, WA & 1 & 2012 & Lustre, MT & 2 & $\ldots$ & $\ldots$ & $\ldots$ \\
\hline 1995 & Waitsburg, WA & 1 & 2012 & Plentywood, MT & 1 & $\ldots$ & $\ldots$ & $\ldots$ \\
\hline 1995 & Walla Walla, WA & 2 & $\ldots$ & $\ldots$ & $\ldots$ & $\ldots$ & $\ldots$ & $\ldots$ \\
\hline 2002 & Fresno, CA & 2 & $\ldots$ & $\ldots$ & $\ldots$ & $\ldots$ & $\ldots$ & $\ldots$ \\
\hline 2002 & Pullman, WA & 1 & $\ldots$ & $\ldots$ & $\ldots$ & $\ldots$ & $\ldots$ & $\ldots$ \\
\hline 2003 & Culdesac, ID & 1 & $\ldots$ & $\ldots$ & $\ldots$ & $\ldots$ & $\ldots$ & $\ldots$ \\
\hline 2003 & Genesee, ID & 2 & $\ldots$ & $\ldots$ & $\ldots$ & $\ldots$ & $\ldots$ & $\ldots$ \\
\hline
\end{tabular}

a Number of isolates. 
A. lentis, and A. rabiei) on solid, quarter-strength PDA medium (1/4 PDA) amended at fungicide concentrations of $0,0.001,0.01,0.1,1$, and $10 \mu \mathrm{g} / \mathrm{ml}$. All amendments were added to autoclaved media after it had cooled to $50^{\circ} \mathrm{C}$, with the final concentration of acetone in amended and nonamended media equaling $0.1 \%$ by volume. All media used in mycelial growth assays were prepared $24 \mathrm{~h}$ prior to experimental use in petri dishes (100 by $15 \mathrm{~mm}$; VWR International).

Fungicide-amended and nonamended media were inoculated by inverting $0.8-\mathrm{cm}$ plugs, excised from the leading edge of 7-day-old PDA cultures, on the center of each petri dish. Two replicate petri dishes were inoculated for each isolate at each fungicide level. The fungicide concentration of $0 \mu \mathrm{g} / \mathrm{ml}$ served as the control. Replicates were incubated in the dark for 11 days at $20 \pm 2^{\circ} \mathrm{C}$. Following this incubation period, colony diameter was measured (in centimeters) at two right angles and averaged for each petri dish to obtain mean radial growth. Mycelial growth for each replicate was converted to percent inhibition compared with the nontreated control, and $\mathrm{EC}_{50}$ values were calculated using the same procedures described in the previous section.

Statistical analyses. In all, 10 isolates were tested per spore germination trial and 20 isolates were tested per mycelial growth trial
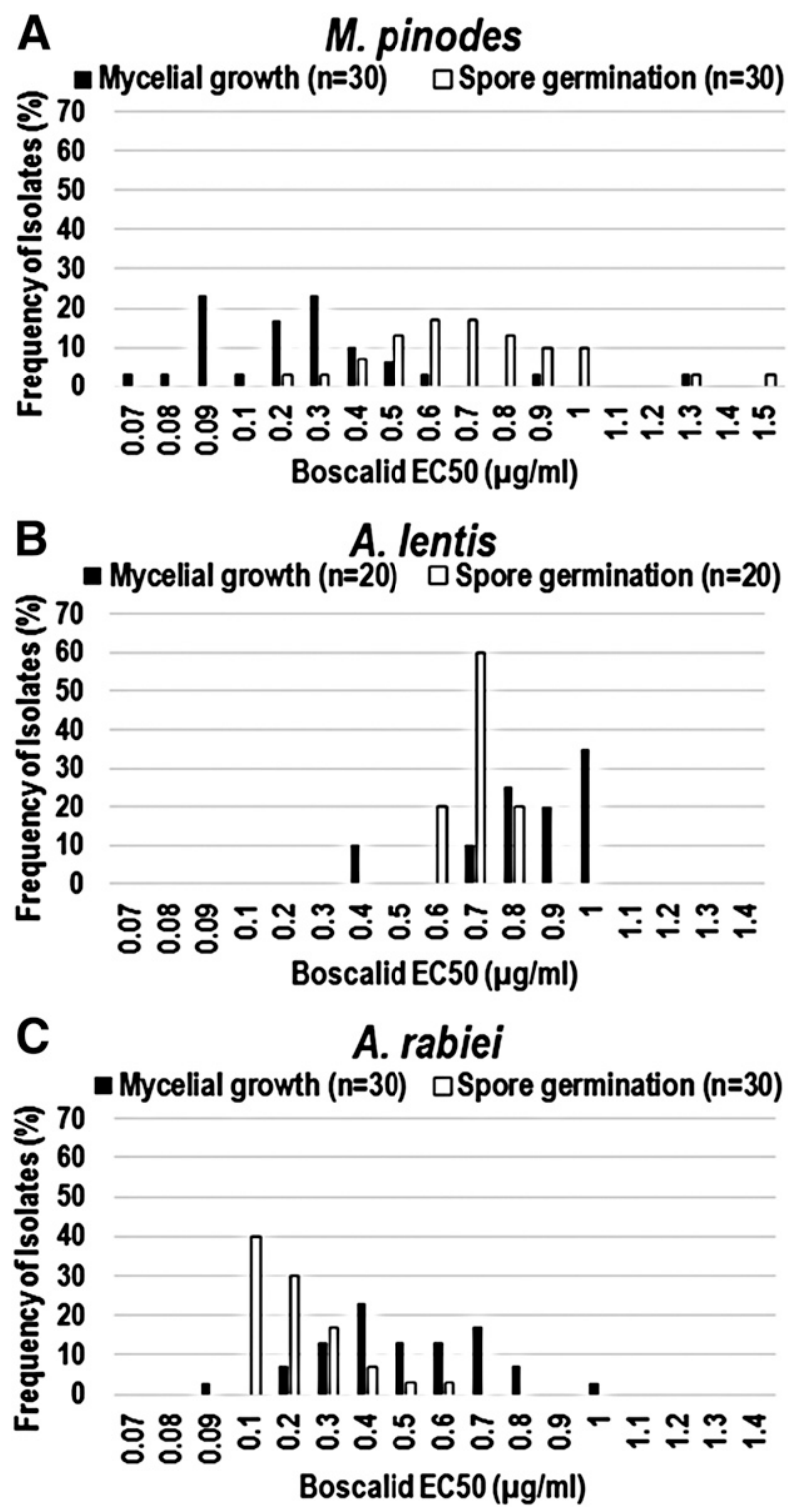

Fig. 1. Boscalid spore germination and mycelial growth effective concentration at which $50 \%$ of growth or germination is inhibited $\left(E C_{50}\right)$ frequency distribution graphs for A, Mycosphaerella pinodes; B, Ascochyta lentis; and C, A. rabiei. for boscalid and prothioconazole sensitivity assays. An arbitrarily selected internal control isolate (AL1974) was tested according to assay reproducibility tests established by Wong and Wilcox (2000). Only trials that satisfied the assay reproducibility requirements (a 95\% confidence interval for the average growth of the internal control isolate) were included in further analyses.

For all experiments, isolates were arranged in a completely randomized design with two replicate plates per isolate. Frequency distributions of $\mathrm{EC}_{50}$ values for isolate populations were determined for each fungicide. Sensitivity profiles were analyzed using the general linear model procedure (PROC GLM) in SAS (version 9.3; SAS Institute, Inc. Cary, NC). Analyses of variance were calculated for each species: fungicide combination separately. Means from mycelial growth and germination assays were compared using Tukey's honest significant difference test $(\alpha=0.05)$.

\section{Results}

Sensitivity profiles. Differences in boscalid sensitivity were observed among $M$. pinodes $(P<0.001)$, A rabiei $(P<0.001)$, and $A$. lentis $(P<0.001)$ isolate populations for both conidial germination and mycelial growth assays (Fig. 1). No significant difference was observed between replications for $M$. pinodes $(P=0.448 ; 0.195)$, A. lentis $(P=0.886 ; 0.961)$, or $A$. rabiei $(P=0.170 ; 0.776)$ for spore germination or mycelial growth assays. Boscalid $\mathrm{EC}_{50}$ values for $A$. rabiei ranged from 0.055 to $0.584 \mu \mathrm{g} / \mathrm{ml}\left(\mathrm{EC}_{50}\right.$ mean $\left.=0.171 \mu \mathrm{g} / \mathrm{ml}\right)$ for conidial germination assays and from 0.084 to $0.957 \mu \mathrm{g} / \mathrm{ml}\left(\mathrm{EC}_{50}\right.$ mean $=$ $0.443 \mu \mathrm{g} / \mathrm{ml}$ ) for mycelial growth assays, representing a 10.6-fold and an 11.4-fold variation factor ( $\mathrm{EC}_{50}$ maximum to $\mathrm{EC}_{50}$ minimum), respectively. Boscalid $\mathrm{EC}_{50}$ values for $M$. pinodes ranged from 0.150 to $1.427 \mu \mathrm{g} / \mathrm{ml}\left(\mathrm{EC}_{50}\right.$ mean $\left.=0.669 \mu \mathrm{g} / \mathrm{ml}\right)$ for conidial germination assays and from 0.064 to $1.289 \mu \mathrm{g} / \mathrm{ml}\left(\mathrm{EC}_{50}\right.$ mean $\left.=0.258 \mu \mathrm{g} / \mathrm{ml}\right)$ for mycelial growth assays, representing a 9.5 -fold and a 20 -fold variation factor, respectively. Boscalid $\mathrm{EC}_{50}$ values for A. lentis ranged from 0.560 to $0.749 \mu \mathrm{g} / \mathrm{ml}\left(\mathrm{EC}_{50}\right.$ mean $\left.=0.639 \mu \mathrm{g} / \mathrm{ml}\right)$ for conidial germination assays and from 0.321 to $0.976 \mu \mathrm{g} / \mathrm{ml}\left(\mathrm{EC}_{50}\right.$ mean $=$ $0.791 \mu \mathrm{g} / \mathrm{ml}$ ) for mycelial growth assays, representing a 1.3-fold and a 3-fold variation factor, respectively (Table 2).

Differences in fluxapyroxad sensitivity were observed among $M$. pinodes $(P<0.001)$, A. lentis $(P<0.001)$, and A. rabiei $(P<$ 0.001 ) isolate populations (Fig. 2), although no significant difference was observed among replications for $M$. pinodes $(P=0.325)$, A. lentis $(P=0.471)$, or A. rabiei $(P=0.697)$. Fluxapyroxad $\mathrm{EC}_{50}$ values from mycelial growth assays ranged from 0.013 to $0.109 \mu \mathrm{g} / \mathrm{ml}$ $\left(\mathrm{EC}_{50}\right.$ mean $\left.=0.050 \mu \mathrm{g} / \mathrm{ml}\right)$ for $M$. pinodes, from 0.510 to $0.990 \mu \mathrm{g} / \mathrm{ml}\left(\mathrm{EC}_{50}\right.$ mean $\left.=0.763 \mu \mathrm{g} / \mathrm{ml}\right)$ for A. lentis, and from 0.006 to $0.164 \mu \mathrm{g} / \mathrm{ml}\left(\mathrm{EC}_{50}\right.$ mean $\left.=0.057 \mu \mathrm{g} / \mathrm{ml}\right)$ for $A$. rabiei, respectively. Fluxapyroxad sensitivity profiles thus represent an 8.4fold, 1.9-fold, and 27-fold variation factor for M. pinodes, A. lentis, and A. rabiei, respectively (Table 2).

Differences in prothioconazole sensitivity were observed among M. pinodes $(P<0.001)$, A. lentis $(P<0.001)$, and A. rabiei $(P=$ $0.0015)$ isolate populations (Fig. 3), although no significant difference was observed between replications for $M$. pinodes $(P=$ $0.318)$, A. lentis $(P=0.405)$, or A. rabiei $(P=0.183)$. Prothioconazole $\mathrm{EC}_{50}$ values from mycelial growth assays ranged from 0.252 to $0.826 \mu \mathrm{g} / \mathrm{ml}\left(\mathrm{EC}_{50}\right.$ mean $\left.=0.541 \mu \mathrm{g} / \mathrm{ml}\right)$ for $M$. pinodes, from 0.257 to $0.973 \mu \mathrm{g} / \mathrm{ml}\left(\mathrm{EC}_{50}\right.$ mean $\left.=0.604 \mu \mathrm{g} / \mathrm{ml}\right)$ for A. lentis, and from 0.026 to $0.834 \mu \mathrm{g} / \mathrm{ml}$ (mean $\mathrm{EC}_{50}=0.283 \mu \mathrm{g} / \mathrm{ml}$ ) for $A$. rabiei, respectively. Prothioconazole sensitivity profiles thus represent a 3.2-fold, 3.7-fold, and 32-fold variation factor for M. pinodes, A. lentis, and A. rabiei, respectively (Table 2).

Determination of discriminatory dose. A single discriminatory dose of $1 \mu \mathrm{g} / \mathrm{ml}$ a.i. was chosen based on the frequency distribution of $\mathrm{EC}_{50}$ values of $M$. pinodes, $A$. lentis, and A. rabiei determined in the in vitro mycelial growth assays for all three fungicides. No resistant isolates were found among those tested here and, subsequently, no in vivo assays were performed. Therefore, the selection of this single dose was somewhat subjective, especially considering that resistance to these three fungicides is known to be incremental in other fungi. This dose will be used with caution, with the understanding 
that the true shift which will result in practical field resistance to these fungicides is not known at this time.

\section{Discussion}

This study reports on the sensitivity of $M$. pinodes, A. lentis, and $A$. rabiei populations to boscalid, fluxapyroxad, and prothioconazole. The information presented here is essential for future monitoring of SDHI and DMI resistance in AB pathogens and for the implementation of resistance management programs.

Sensitivity to boscalid was determined based on the inhibition of conidial germination and mycelial growth because boscalid is known to be effective against all stages of fungal development (Stammler et al. 2007). In this study, boscalid $\mathrm{EC}_{50}$ values for $A$. rabiei from conidial germination assays were consistent with the range $(0.0177$ to $0.4960 \mu \mathrm{g} / \mathrm{ml})$ and mean $(0.1903 \mu \mathrm{g} / \mathrm{ml})$ previously reported for A. rabiei by Wise et al. (2008) and, although slightly higher, $\mathrm{EC}_{50}$ values for $A$. rabiei from mycelial growth assays were also congruent with previously reported results (Thaher 2013). M. pinodes and $A$. lentis isolates exhibited a narrow range $(<10$-fold $)$ of $\mathrm{EC}_{50}$ values from boscalid conidial germination assays; however, the sensitivity profile from mycelial growth assays was substantially larger $(2 \times)$. Similarly, Botrytis cinerea isolates had greater variation in $\mathrm{EC}_{50}$ values from mycelial growth compared with spore germination assays, although sensitivity profiles were broad using either assay type (Myresiotis et al. 2008; Zhang et al. 2007). Substantial variation $(17 \times)$ in the sensitivity of baseline Alternaria solani isolates to boscalid from conidial germination assays also has been reported (Pasche et al. 2005).

Comparison of conidial germination and mycelial growth assays for evaluating the inhibitory effects of boscalid indicate that Ascochyta rabiei and A. lentis isolates exhibited higher levels of sensitivity to boscalid based on conidial germination assays, while $M$. pinodes isolates had higher levels of sensitivity to boscalid based on mycelial growth assays. Conflicts between sensitivity profiles from conidial germination and mycelial growth assays to boscalid have been reported for other fungal pathogens as well. B. cinerea has been reported to have higher levels of boscalid sensitivity based on inhibition of spore germination, while the sensitivity of Alternaria alternata isolates to boscalid was found to be higher using mycelial growth assays (Avenot et al. 2008; Zhang et al. 2007). Mycelial growth assays were selected for use in standard sensitivity testing associated with fungicide resistance monitoring programs for populations of $\mathrm{AB}$ pathogens, because they are less labor and time intensive than conidial germination assays and may streamline large-scale sensitivity testing. The ability to screen more isolates has greater benefits than the challenges that may be presented by the larger range of $\mathrm{EC}_{50}$ values observed with some mycelial growth assays. Additionally, this study found that sensitivity profiles from mycelial growth assays encompassed the variation observed in spore germination assays, which may indicate a more robust assay type for the Ascochyta isolates tested. Additionally, any shift in sensitivity found during in vitro assays should be confirmed using in vivo assays with the proper control isolates.

Baseline sensitivity to the next-generation SDHI fungicide fluxapyroxad has been determined for limited pathogenic fungi because it is a newer fungicide molecule within the SDHI class. In this study, M. pinodes and Ascochyta lentis isolates exhibited a narrow range of $\mathrm{EC}_{50}$ values for fluxapyroxad (0.013 to 0.109 and 0.550 to $0.990 \mu \mathrm{g} / \mathrm{ml}$, respectively), in contrast to the broader range of $\mathrm{EC}_{50}$ values $(0.006$ to $0.16 \mu \mathrm{g} / \mathrm{ml})$ exhibited by $A$. rabiei isolates. B. cinerea and Alternaria alternata isolates have also been reported as having a relatively broad range of $\mathrm{EC}_{50}$ values for fluxapyroxad ( 0.07 to $7.1 \mu \mathrm{g} / \mathrm{ml}$ and $<0.01$ to $0.311 \mu \mathrm{g} / \mathrm{ml}$, respectively) (Amiri et al. 2014; Avenot et al. 2014). Similarly, previous reports for penthiopyrad, a closely related SDHI fungicide, indicate that Ascochyta rabiei isolates also had a broad range of $\mathrm{EC}_{50}$ values, in contrast to the narrow range of $\mathrm{EC}_{50}$ values reported for Didymella bryoniae isolates $(0.015$ to $0.057 \mu \mathrm{g} / \mathrm{ml})$ (Thaher et al. 2010; Thomas et al. 2012). Direct comparisons were not made between boscalid and fluxapyroxad sensitivities because technical-grade and formulated product were used, respectively. Unfortunately, technical-grade fluxapyroxad was not available. Technical-grade boscalid was chosen because previous studies had been performed using technical-grade product, and the use of technical-grade product avoids interference from inert ingredients.

Fluxapyroxad was registered for use on pulse crops in 2012 under the trade name Priaxor (BASF Corporation), a blend of fluxapyroxad and the QoI fungicide pyraclostrobin. The application of fungicides with different modes of action is a recommended resistance management strategy for limiting the development of fungicide insensitivity in pathogen populations (Brent 1995). Unfortunately, resistance to pyraclostrobin already has been documented in A. rabiei and M. pinodes populations (Bowness 2013; Delgado et al. 2012; Wise et al. 2009), which may result in compromised efficacy of Priaxor, with disease control resulting mainly from the activity of fluxapyroxad. This has been documented for the closely related premix fungicide Pristine (pyraclostrobin + boscalid) against pyraclostrobin-resistant Alternaria alternata, A. solani, and D. bryoniae populations, where the efficacy of the fungicide was attributed solely to boscalid activity (Avenot et al. 2008; Pasche et al. 2005; Thomas et al. 2012). Because QoI resistance development in these fungi and in Ascochyta rabiei has been attributed to the G143A mutation, which results in no disease control (Delgado et al. 2012), pyraclostrobin does not represent a viable partner for resistance management. Functionally, this results in the use of fluxapyroxad as a sole active ingredient, a concept that must be successfully communicated to growers for effective resistance management practices to be employed.

Although slightly higher, the mean prothioconazole $\mathrm{EC}_{50}$ value for A. rabiei reported in this study $(0.28 \mu \mathrm{g} / \mathrm{ml})$ was similar to the mean $(0.18 \mu \mathrm{g} / \mathrm{ml})$ previously reported by Wise et al. (2011). The variation

Table 2. Range, mean, and variation for sensitivity profiles of Mycosphaerella pinodes, Ascochyta lentis, and A. rabiei isolates to boscalid, fluxapyroxad, and prothioconazole

\begin{tabular}{|c|c|c|c|c|c|}
\hline \multirow[b]{2}{*}{ Fungicide } & \multirow[b]{2}{*}{ Assay } & \multirow[b]{2}{*}{ Species } & \multicolumn{3}{|c|}{$\mathrm{EC}_{50}(\mu \mathrm{g} / \mathrm{ml})^{\mathrm{a}}$} \\
\hline & & & Range & Mean & Vf \\
\hline \multirow[t]{6}{*}{ Boscalid } & Conidial germination & M. pinodes & $0.150-1.427$ & 0.669 & 9.5 \\
\hline & $\ldots$ & A. lentis & $0.560-0.749$ & 0.639 & 1.3 \\
\hline & $\ldots$ & A. rabiei & $0.055-0.584$ & 0.171 & 11 \\
\hline & Mycelial growth & M. pinodes & $0.064-1.289$ & 0.258 & 20 \\
\hline & $\ldots$ & A. lentis & $0.321-0.976$ & 0.791 & 3 \\
\hline & $\ldots$ & A. rabiei & $0.084-0.957$ & 0.443 & 11 \\
\hline \multirow[t]{3}{*}{ Fluxapyroxad } & Mycelial growth & M. pinodes & $0.013-0.109$ & 0.050 & 8.4 \\
\hline & $\ldots$ & A. lentis & $0.510-0.990$ & 0.763 & 1.9 \\
\hline & $\ldots$ & A. rabiei & $0.006-0.164$ & 0.057 & 27 \\
\hline \multirow[t]{3}{*}{ Prothioconazole } & Mycelial growth & M. pinodes & $0.252-0.826$ & 0.541 & 3.2 \\
\hline & $\ldots$ & A. lentis & $0.257-0.973$ & 0.604 & 3.7 \\
\hline & $\ldots$ & A. rabiei & $0.026-0.834$ & 0.283 & 32 \\
\hline
\end{tabular}

${ }^{\mathrm{a}} \mathrm{EC}_{50}=$ effective concentration that inhibits germination or growth by $50 \%$ and $\mathrm{Vf}=$ variation factor $=$ highest $\mathrm{EC}_{50}$ value divided by the lowest $\mathrm{EC}_{50}$ value. 
factor was substantially broader $(5.5 x)$ in the current study and displayed a bimodal pattern. A bimodal pattern can indicate the separation of distinct sensitive and insensitive populations; however, the $A$. rabiei isolates used in this study had no previous exposure to DMI fungicides and, therefore, this bimodal curve can likely be attributed to inherent variation in isolate sensitivity (Brent and Holloman 2007). A bimodal pattern also has been reported in baseline prothioconazole sensitivity in M. pinodes (Delgado et al. 2011). A. rabiei isolates tested in this study represented a subset of the baseline isolates used by Wise et al. (2011), and it is unclear why the sensitivity profiles established by this current study are not in complete agreement with those previously published. We were unable to compare individual $\mathrm{EC}_{50}$ values between studies, which could have provided insight into the variation seen in A. rabiei sensitivity profiles. These results serve as confirmation that, although every effort was made to repeat the methods used in previous research, inherent differences in variables such as incubation conditions and researcher subjectivity can result in slight differences in results. This further emphasizes the need for reference isolates in addition to standardized evaluation methods and confirmation of resistance using in vivo methods.
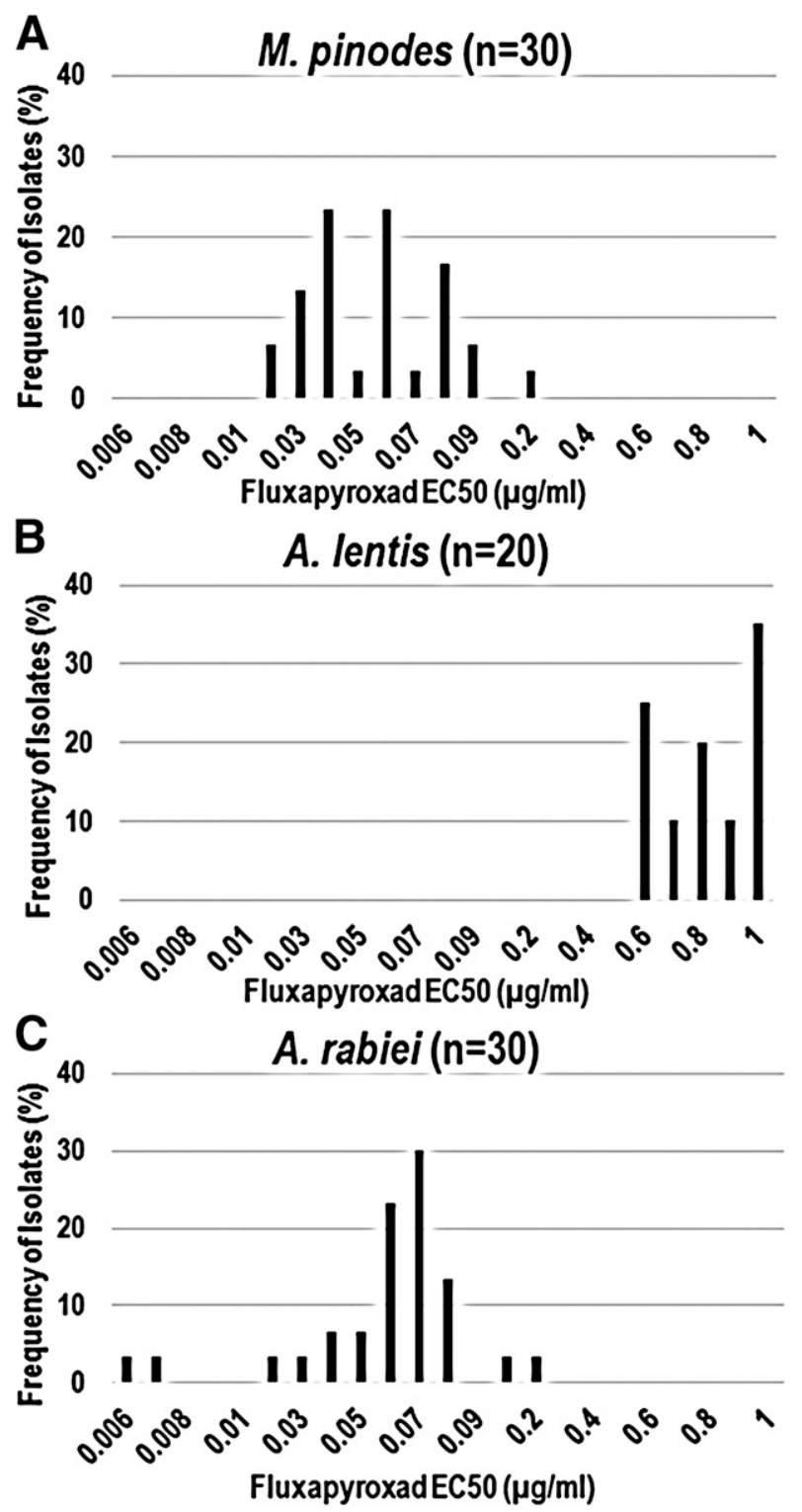

Fig. 2. Fluxapyroxad mycelial growth effective concentration at which $50 \%$ of growth is inhibited $\left(E_{50}\right)$ frequency distribution graphs for A, Mycosphaerella pinodes; $\mathbf{B}$, Ascochyta lentis; and C, A. rabiei.
The range and mean prothioconazole $\mathrm{EC}_{50}$ values obtained for the $2012 M$. pinodes population evaluated here was similar to that observed for a baseline population (Delgado et al. 2011). Interestingly, the $M$. pinodes baseline was reported to have a bimodal shape, with mean $\mathrm{EC}_{50}$ values of the subgroups of 0.8617 and $2.7449 \mu \mathrm{g} / \mathrm{ml}$. The values reported here actually fall within the lower subgroup of that population. These findings indicate that methods used were consistent with previously used methods and that no shift was detected in $M$. pinodes to prothioconazole, and support the use of the $2012 \mathrm{~A}$. lentis population evaluated in this research as a functional baseline population. The range of prothioconazole $\mathrm{EC}_{50}$ values for $M$. pinodes and $A$. lentis isolates was similar to the range reported for Cercospora beticola $(0.60$ to $0.911 \mu \mathrm{g} / \mathrm{ml})$, although the variation was more pronounced in the current study (Secor et al. 2008). Similar to A. lentis isolates, $C$. beticola populations had previous exposure to DMI fungicides and, thus, did not represent a true baseline group, which may account for the higher sensitivity range seen in these isolates in comparison with baseline $A$. rabiei isolates. This is consistent with results reported by Wise et al. (2011) which indicate that $A$. rabiei isolates exposed to prothioconazole for less than one growing season exhibited a significant decrease in sensitivity compared with baseline

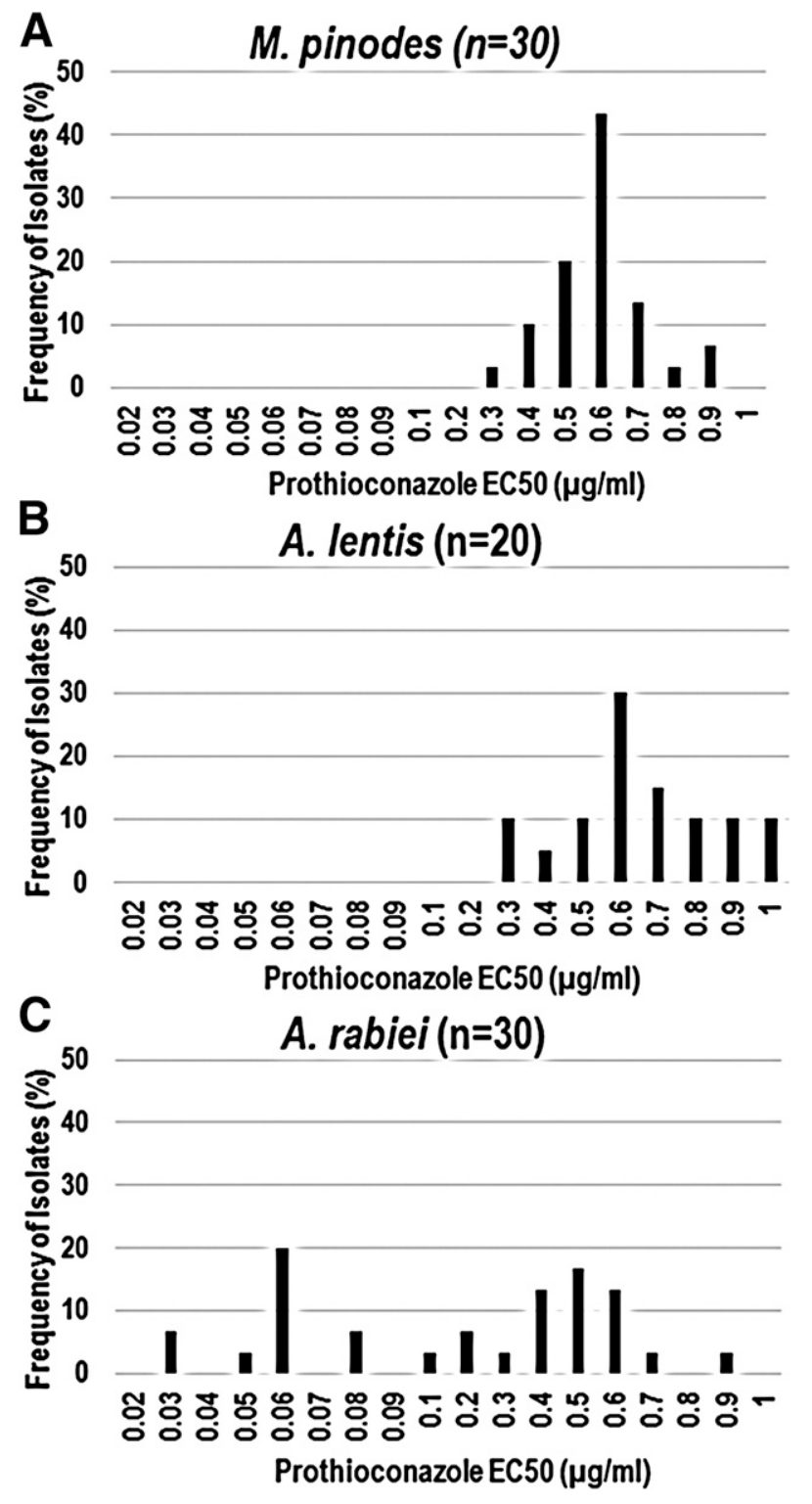

Fig. 3. Prothioconazole mycelial growth effective concentration at which $50 \%$ of growth is inhibited $\left(E_{50}\right)$ frequency distribution graphs for $\mathbf{A}$, Mycosphaerella pinodes; $\mathbf{B}$, Ascochyta lentis; and C, A. rabiei. 
populations. It is hypothesized by those authors that this may have been due to the small number of isolates evaluated and that no reductions in efficacy were observed under field conditions (Wise et al. 2011).

A single discriminatory concentration of $1 \mu \mathrm{g} / \mathrm{ml}$ a.i. was selected across all fungicides (boscalid, fluxapyroxad, and prothioconazole) for each species (M. pinodes, A. lentis, and A. rabiei). A uniform discriminatory dose across all species-fungicide combinations was chosen to maintain efficiency and accuracy when testing large numbers of isolates. Although the original baseline for $M$. pinodes contained several isolates with $\mathrm{EC}_{50}$ values greater than $1 \mu \mathrm{g} / \mathrm{ml}$, this was not observed with 2012 isolates and, therefore, a discriminatory dose reflective of those values was chosen. The single discriminatory concentration and sensitivity profiles established by this research will be used to monitor for pathogen shifts in fungicide sensitivity and to determine how these shifts may impact $\mathrm{AB}$ management programs. Any isolates displaying growth at the discriminatory dose will be further examined using a full range of in vitro and in vivo fungicide concentrations. The lack of true baseline A. lentis isolates does increase the difficulty in characterizing sensitivity shifts to SDHI and DMI fungicides. However, exposure has been minimal, and field resistance to SDHI and DMI fungicides has not been reported, indicating that practical resistance has not developed. The sensitivity profiles established in this study are an informative and necessary tool for capturing future sensitivity shifts that may result in disease control failure.

To the best of our knowledge, there are no reports of $\mathrm{AB}$ pathogen populations displaying resistance to boscalid, fluxapyroxad, or prothioconazole at this time. Resistance to SDHI and DMI fungicides has been reported for other fungal pathogens, although substantial variation in the presentation of this resistance is evident (Koller et al. 1997; Sierotzki and Scalliet 2013; Wong and Midland 2007; Ypema et al. 1997). Due to this variation, a decrease in fungicide sensitivity may not always translate into practical control problems, although it still provides a useful indication of the presence of risk. For example, a sixfold reduction in Colletotrichum cereal sensitivity to the DMI fungicide propiconazole only caused a decline in fungicide efficacy at $1 / 16$ th the label rate, which is not likely to affect the field performance of the fungicide (Wong and Midland 2007), whereas the 1,000-fold decrease observed in Cercospora beticola isolates to the DMI fungicide tetraconazole did result in unacceptable levels of disease control at recommended field application rates (Bolton et al. 2012). Additionally, more than 27 mutations that confer resistance to next-generation SDHI fungicides have been reported from field populations of different pathogens, with mutations conveying a range of resistance factors and displaying species-dependent resistance patterns (Sierotzki and Scalliet 2013). In populations of Alternaria sol$a n i$, an approximately 10 -fold shift in in vitro sensitivity resulted in differences in disease control in azoxystrobin and pyraclostrobin, whereas a 2-fold shift in in vitro sensitivity to trifloxystrobin did not (Pasche et al. 2004).

In summary, the research presented here provides critical information necessary for a successful fungicide resistance monitoring program for pulse crops by establishing functional baseline sensitivity profiles and single discriminatory concentrations for $M$. pinodes, $A$. lentis, and A. rabiei to boscalid, fluxapyroxad, and prothioconazole. Although previous research indicates that not all mutations observed in SDHI fungicides result in cross-resistance, it is recommended that boscalid and fluxapyroxad not be used in the same spray program for resistance management purposes. Single discriminatory concentrations established in this study will be used to continue evaluating A. rabiei, A. lentis, and M. pinodes isolates for resistance development to SDHI and DMI fungicides. This information, in conjunction with previous research on fungicide sensitivity in A. rabiei and $M$. pinodes populations (Bowness 2013; Thaher 2013; Thaher et al. 2010; Wise et al. 2008, 2011), will facilitate our ability to monitor pathogen sensitivity, determine when shifts in sensitivity occur, and make informed disease management recommendations with the goal of prolonging the use of the limited fungicide classes available for the management of $\mathrm{AB}$ in pulse crops.

\section{Acknowledgments}

This project was funded by a grant from the Montana Department of Agriculture Specialty Crop Block Grant. We thank W. Chen and F. Dugan for the use of $A$ rabiei isolate collections, the BASF Corporation for providing technical- and product-grade formulations of the fungicides, and F. Dugan for a thorough review of the manuscript.

\section{Literature Cited}

Amiri, A., Heath, S. M., and Peres, N. A. 2014. Resistance to fluopyram, fluxapyroxad, and penthiopyrad in Botrytis cinerea from strawberry. Plant Dis. 98:532-539.

Avenot, H. F., and Michailides, T. J. 2007. Resistance to boscalid fungicide in Alternaria alternata isolates from pistachio in California. Plant Dis. 91: 1345-1350.

Avenot, H., Morgan, D. P., and Michailides, T. J. 2008. Resistance to pyraclostrobin, boscalid and multiple resistance to Pristine (R) (pyraclostrobin plus boscalid) fungicide in Alternaria alternata causing Alternaria late blight of pistachios in California. Plant Pathol. 57:135-140.

Avenot, H. F., Van Den Biggelaar, H., Morgan, D. P., Moral, J., Joosten, M., and Michailides, T. J. 2014. Sensitivities of baseline isolates and boscalid-resistant mutants of Alternaria alternata from pistachio to fluopyram, penthiopyrad, and fluxapyroxad. Plant Dis. 98:197-205.

Bolton, M. D., Rivera-Varas, V., Mendoza, L. E. D. R., Khan, M. F. R., and Secor, G. A. 2012. Efficacy of variable tetraconazole rates against Cercospora beticola isolates with differing in vitro sensitivities to DMI fungicides. Plant Dis. 96: 1749-1756.

Bowness, R. 2013. Sensitivity of Mycosphaerella pinodes to pyraclostobin and optimizing fungicide application in field pea. Master's thesis, University of Alberta, Edmonton, Alberta, Canada.

Brent, K. J. 1995. Fungicide resistance in crop pathogens. How can it be managed? FRAC Monograph No. 1, Crop Life International, Brussels.

Brent, K. J., and Holloman, D. W. 2007. Fungicide resistance: The assessment of risk. FRAC Monograph No. 2, Crop Life International, Brussels.

Bretag, T. W., Keane, P. J., and Price, T. V. 2006. The epidemiology and control of Ascochyta blight in field peas: A review. Aust. J. Agric. Res. 57:883-902.

Burrows, M. 2013. High Plains Integrated Pest Management: Pulse crop foliar fungicides. Online publication. http://wiki.bugwood.org/HPIPM

Chang, K. F., Ahmed, H. U., Hwang, S. F., Gossen, B. D., Strelkov, S. E., Blade, S. F., and Turnbull, G. D. 2007. Sensitivity of field populations of Ascochyta rabiei to chlorothalonil, mancozeb and pyraclostrobin fungicides and effect of strobilurin fungicides on the progress of Ascochyta blight of chickpea. Can. J. Plant Sci. 87:937-944.

Chen, F., Liu, X., and Schnabel, G. 2013. Field strains of Monilinia fructicola resistant to both MBC and DMI fungicides isolated from stone fruit orchards in the Eastern United States. Plant Dis. 97:1063-1068.

Chen, W., Sharma, H. C., and Muehlbauer, F. J. 2011. Compendium of Chickpea and Lentil Disease and Pests. American Phytopathological Society, St. Paul, $\mathrm{MN}$.

Chongo, G., Buchwaldt, L., Gossen, B. D., Lafond, G. P., May, W. E., Johnson, E. N., and Hogg, T. 2003. Foliar fungicides to manage Ascochyta blight Ascochyta rabiei of chickpea in Canada. Can. J. Plant Pathol. 25:135-142.

Davidson, J. A., and Kimber, R. B. E. 2007. Integrated disease management of Ascochyta blight in pulse crops. Eur. J. Plant Pathol. 119:99-110.

Delgado, J. A., Goswami, R. S., Harveson, R. M., Urrea, C. A., Beran, D., and Markell, S. G. 2012. First report of Ascochyta blight caused by QoI-resistant isolates of Ascochyta rabiei in chickpea fields of Nebraska and South Dakota. Plant Dis. 96:1073.

Delgado, J. A., Stoppler, T., Gossen, B. D., Chang, K. F., Dugan, F., Markell, S., and Goswami, R. S. 2011. Sensitivity of Ascochyta pinodes populations to prothioconazole. (Abstr.) Can. J. Plant Sci. 91:388.

Forster, H., Nguyen, K., Vilchez, M., Connell, J., and Adaskaveg, J. 2011. High levels of natural resistance against selected DMI fungicides in populations of Fusicladosporium carpophilum but not Alternaria spp. from almond. (Abstr.) Phytopathology 101:S54.

Fungicide Resistance Action Committee. 2015. Fungicides sorted by mode of action. FRAC Code List. Online publication: http://www.frac.info/docs/defaultsource/publications/frac-code-list/frac-code-list-2015-finalC2AD7AA36764. pdf?sfvrsn=4

Gan, Y. T., Siddique, K. H. M., Macleod, W. J., and Jayakumar, P. 2006 Management options for minimizing the damage by Ascochyta blight (Ascochyta rabiei) in chickpea (Cicer arietinum L.). Field Crops Res. 97:121-134.

Gudmestad, N. C., Arabiat, S., Miller, J. S., and Pasche, J. S. 2013. Prevalence and impact of SDHI fungicide resistance in Alternaria solani. Plant Dis. 97: 952-960.

Jo, Y. K., Niver, A. L., Rimelspach, J. W., and Boehm, M. J. 2006. Fungicide sensitivity of Sclerotinia homoeocarpa from golf courses in Ohio. Plant Dis. 90:807-813.

Koller, W., Wilcox, W. F., Barnard, J., Jones, A. L., and Braun, P. G. 1997 Detection and quantification of resistance of Venturia inaequalis populations to sterol demethylation inhibitors. Phytopathology 87:184-190.

Kraft, J. M., and Pfleger, F. L. 2001. Compendium of Pea Diseases and Pests American Phytopathological Society, St. Paul, MN. 
Lee, C. 2011. Montana's Pulse Industry: How it has Developed, Economic Impact, \& Potential Growth. Montana Department of Agriculture, Helena.

Luo, C.-X., and Schnabel, G. 2008. Adaptation to fungicides in Monilinia fructicola isolates with different fungicide resistance phenotypes. Phytopathology 98: 230-238.

Myresiotis, C. K., Bardas, G. A., and Karaoglanidis, G. S. 2008. Baseline sensitivity of Botrytis cinerea to pyraclostrobin and boscalid and control of anilinopyrimidine- and benzimidazole-resistant strains by these fungicides. Plant Dis. 92:1427-1431.

Pasche, J. S., Piche, L. M., and Gudmestad, N. C. 2005. Effect of the F129L mutation in Alternaria solani on fungicides affecting mitochondrial respiration. Plant Dis. 89:269-278.

Pasche, J. S., Wharam, C. M., and Gudmestad, N. C. 2004. Shift in sensitivity of Alternaria solani in response to Q(o)I fungicides. Plant Dis. 88:181-187.

Russel, P. E. 2004. Sensitivity Baselines in Fungicide Resistance Research and Management. CropLife International, Fungicide Resistance Action Committee, Brussels.

Secor, G., Rivera, V., and Khan, M. 2008. Sensitivity of Cercospora beticola to foliar fungicides in 2007, Sugarbeet Research Extension Report. North Dakota State University, Fargo, ND.

Sierotzki, H., and Scalliet, G. 2013. A review of current knowledge of resistance aspects for the next-generation succinate dehydrogenase inhibitor fungicides. Phytopathology 103:880-887.

Stammler, G., Brix, H. D., Nave, B., Gold, R., and Schoefl, U. 2007. Studies on the biological performance of boscalid and its mode of action. In: 15th Int. Reinhardsbrunn Symp. Modern Fungicides and Antifungal Compounds, Friedrichroda, Germany.

Thaher, N. H. 2013. Fungicide insensitivity in Ascochyta rabiei in Saskatchewan. Masters' thesis, University of Guelph, Guelph, Ontario, Canada

Thaher, N. H., Gossen, B. D., and McDonald, M. 2010. Baseline sensitivity of Ascochyta rabiei to penthiopyrad, a new SDHI fungicide. (Abstr.) Phytopathology 100:S125.
Thomas, A., Langston, D. B., Jr., and Stevenson, K. L. 2012. Baseline sensitivity and cross-resistance to succinate-dehydrogenase-inhibiting and demethylationinhibiting fungicides in Didymella bryoniae. Plant Dis. 96:979-984.

Tivoli, B., and Banniza, S. 2007. Comparison of the epidemiology of Ascochyta blights on grain legumes. Eur. J. Plant Pathol. 119:59-76.

United States Department of Agriculture \& National Agriculture Statistics Service. 2014. Crop production 2013 summary. Online: http://usda.mannlib.cornell. edu/usda/nass/CropProdSu//2010s/2014/CropProdSu-01-10-2014.pdf

Wise, K. A., Bradley, C. A., Pasche, J. S., Gudmestad, N. C., Dugan, F. M., and Chen, W. 2008. Baseline sensitivity of Ascochyta rabiei to azoxystrobin, pyraclostrobin, and boscalid. Plant Dis. 92:295-300.

Wise, K. A., Bradley, C. A., Markell, S., Pasche, J., Delgado, J. A., Goswami, R. S., and Gudmestad, N. C. 2011. Sensitivity of Ascochyta rabiei populations to prothioconazole and thiabendazole. Crop Prot. 30:1000-1005.

Wise, K. A., Bradley, C. A., Pasche, J. S., and Gudmestad, N. C. 2009. Resistance to QoI fungicides in Ascochyta rabiei from chickpea in the Northern Great Plains. Plant Dis. 93:528-536.

Wong, F. P., and Midland, S. L. 2007. Sensitivity distributions of California Populations of Colletotrichum cereale to the DMI Fungicides propiconazole, myclobutanil, tebuconazole, and triadimefon. Plant Dis. 91:1547-1555.

Wong, F. P., and Wilcox, W. F. 2000. Distribution of baseline sensitivities to azoxystrobin among isolates of Plasmopara viticola. Plant Dis. 84:275-281.

Wyand, R. A., and Brown, J. K. M. 2005. Sequence variation in the CYP51 gene of Blumeria graminis associated with resistance to sterol demethylase inhibiting fungicides. Fungal Genet. Biol. 42:726-735.

Ye, G., McNeil, D. L., and Hill, G. D. 2000. Lentil Ascochyta blight and breeding for its resistance. N. Z. Plant Prot. 53:97-102.

Ypema, H. L., Ypema, M., and Gubler, W. D. 1997. Sensitivity of Uncinula necator to benomyl, triadimefon, myclobutanil, and fenarimol in California. Plant Dis. 81:293-297.

Zhang, C. Q., Yuan, S. K., Sun, H. Y., Qi, Z. Q., Zhou, M. G., and Shu, G. N. 2007. Sensitivity of Botrytis cinerea from vegetable greenhouses to boscalid. Plant Pathol. 56:646-653. 